results from each, making it less easy for the reader to discern factors related to engine tests with widely different conditions of fuel, combustion, temperature, and pressure.

The later chapters, on carbon, lacquer and sludge deposits, piston ring sticking, and engine maintenance, are most interesting and of great value. They would have been even more valuable if the author had given a little more than a hint of the type of engine tested, and, in the case of diesel engines, the fuel used.

The last chapter is concerned with the practical testing of lubricating oils-a subject ample for a book on its own. The author treats it briefly, although with authority. The earlier text indicates that the author has conducted many hundreds of hours of research, and has considerable experience on the practical testing of lubricating oils. This experience would be worth setting out in print. The author rightly stresses the difficulty and importance of reproducibility in all engine tests of lubricating oils.

The work is commendably illustrated with many simple graphs, is practical, and fills a gap between the short published findings of various laboratories on engine deposits and the large number of books on advanced chemistry of lubricating oil.

The translator from the Dutch has served the author and reader well, but has stopped short at the text. Many English-speaking readers would have been grateful had the metric units been transposed into those with which they commonly work.

K. G. FIRTH

\section{PETROLEUM GEOLOGY}

\section{Petroleum Geology}

By Dr. E. N. Tiratsoo. Pp. xix $+450+8$ plates. (London: Methuen and Co., Ltd., 1951.) 42s, net. Petroleum Geology

By Prof. Kenneth K. Landes. Pp. $x i+660$. (New York : John Wiley and Sons, Inc. ; London: Chapman and Hall, Ltd., 1951.) $80 \mathrm{~s}$. net.

7 HE geology of oilfields has become such an immense subject that it is impossible to cover the whole range adequately within the confines of a single volume. Both these books are worthy attempts to do so; but both may be criticized for attermpting too wide a field. They are primarily books for students, but, even making allowance for this, their value would have been greater if the non-geological sections could have been shortened to allow of more adequate treatment of the important descriptions of the geology of the oilfields of the world. Dr. E. N. Tiratsoo, for example, uses up many pages on topographical survey technique, geophysical technique, correlation of wells and drilling muds, and Prof. K. K. Landes similarly occupies more than a hundred pages on his introduction and on the techniques of drilling and sampling wells.

In Prof. Landes's book the section on the accumula tion of oil and the various types of traps is very good and well illustrated with maps and cross-sections of typical cases, and this leads on to individual descriptions of the oilfields of the United States and then of the rest of the world. There is an abundance of illustrative maps, perhaps unnecessarily many, as there is some repetition, and some of the maps might with advantage be replaced by cross-sections. Some countries receive rather summary treatment through lack of space - Germany, to take a case at random, is covered in two pages, including a small outline map. The final chapter discusses the proved reserves in the known oilfields of the world, giving the estimate in 1949 of 83,000 million barrels, of which 28,000 is in the United States and 32,000 in the Middle East. At the 1949 production-rate these reserves constitute only twenty-two years of assured supply, but no figure is suggested for the reserves resulting from discovery of new fields or from more efficient recovery from the old. In the United States the continental shelf, particularly in the Gulf of Mexico, is expected to contain a large reserve, and there is still large scope for discovery elsewhere, perhaps particularly along the Rocky Mountain front both in Canada and in the United States. Elsewhere in the world the immature stage of exploration in many South American countries, in Russia, Siberia, China and elsewhere is described, and undoubtedly there is abundant scope for new discovery on a large scale.

Dr. Tiratsoo covers the same general ground in his description of the oilfields of the world, but giving less space to the United States and more to Europe and Asia with good illustrative maps and crosssections. His geological time-chart which precedes this chapter is somewhat unsatisfying in that he accepts Hang's classification for Europe as the standard, and for North America he omits most of the stage names which cause so much confusion to European geologists. He shows the Permian as an epoch of the Carboniferous period, which is unusual in American practice. There is no discussion of reserves on the lines of that in Prof. Landes's book, which is perhaps a weakness.

Fither of these books may be confidently recommended for a general survey of the subject, with a great concentration of up-to-date facts. The criticisms stated above are not meant to imply that they are not both good books, but only to express a slight disappointment that they are not better.

\section{ROBERTS'S “HEAT AND THERMO- DYNAMICS"}

Heat and Thermodynamics

By Dr. J. K. Roberts. Revised by Dr. A. R. Miller. Fourth edition. Pp. $\mathrm{xx}+593$. (London and Glasgow : Blackie and Son, Ltd., 1951.) 35s. net.

TOTABLE advances in low-temperature work and in the theory of the solid state have taken place during the eleven years since the last edition of the late Dr. J. K. Roberts's "Heat and Thermodynamics" appeared. The new material incorporated in this, the fourth edition, by Dr. A. R. Miller, brings the book up to date with discussions of experimental work published as recently as 1950. The time was ripe for $a_{0}$ new edition - not that such a book could ever be 'out of date', but simply because new problems have afforded such excellent examples of the application of thermodynamics that their study must surely help the reader to a better understanding of the subject as a whole.

Most of the new work is introduced in the chapter on low temperatures, which includes an account of the Collins helium liquefier, Simon and Swenson's investigation of the liquid-solid equilibrium of helium, the helium vapour-pressure scale of temperature below $5^{\circ} \mathrm{K}$., a discussion of the theory of cooling 